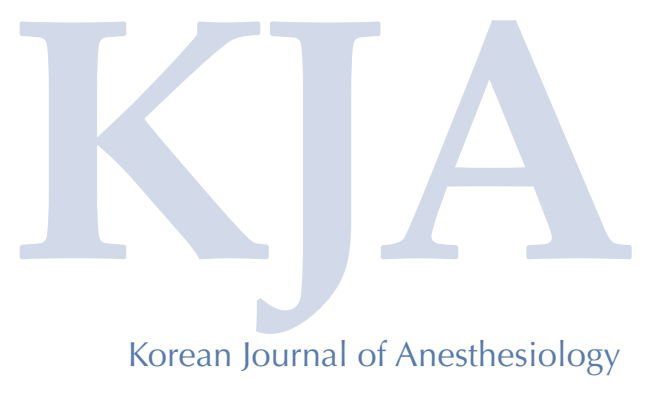

\title{
Airway management of patients with traumatic brain injury / C-spine injury
}

\author{
Jin Yong Jung \\ Department of Anesthesiology and Pain Medicine, Catholic University of Daegu School of Medicine, Daegu, Korea
}

Traumatic brain injury (TBI) is usually combined with cervical spine (C-spine) injury. The possibility of C-spine injury is always considered when performing endotracheal intubation in these patients. Rapid sequence intubation is recommended with adequate sedative or analgesics and a muscle relaxant to prevent an increase in intracranial pressure during intubation in TBI patients. Normocapnia and mild hyperoxemia should be maintained to prevent secondary brain injury. The manual-in-line-stabilization (MILS) technique effectively lessens C-spine movement during intubation. However, the MILS technique can reduce mouth opening and lead to a poor laryngoscopic view. The newly introduced video laryngoscope can manage these problems. The AirWay Scope ${ }^{\circledR}$ (AWS) and AirTraq laryngoscope decreased the extension movement of $\mathrm{C}$-spines at the occiput- $\mathrm{C} 1$ and $\mathrm{C} 2-\mathrm{C} 4$ levels, improving intubation conditions and shortening the time to complete tracheal intubation compared with a direct laryngoscope. The Glidescope ${ }^{\circledR}$ also decreased cervical movement in the $\mathrm{C} 2$-C5 levels during intubation and improved vocal cord visualization, but a longer duration was required to complete intubation compared with other devices. A lightwand also reduced cervical motion across all segments. A fiberoptic bronchoscope-guided nasal intubation is the best method to reduce cervical movement, but a skilled operator is required. In conclusion, a video laryngoscope assists airway management in TBI patients with C-spine injury.

Key Words: Airway management, Cervical cord, Intubation, Traumatic brain injury.

\section{Introduction}

Endotracheal intubation in patients with traumatic brain injury (TBI) and damage to the cervical spine is an important factor in determining life and death. Endotracheal intubation

Corresponding author: Jin Yong Jung, M.D., Ph.D.

Department of Anesthesiology and Pain Medicine, Catholic University of Daegu School of Medicine, 33, Duryugongwon-ro 17gil, Nam-gu, Daegu 705-718, Korea

Tel: 82-53-650-4505, Fax: 82-53-650-4517

E-mail: jychung@cu.ac.kr

Received: December 1, 2014.

Revised: December 8, 2014.

Accepted: December 9, 2014.

Korean J Anesthesiol 2015 June 68(3): 213-219

http://dx.doi.org/10.4097/kjae.2015.68.3.213 failures create the possibility of respiratory arrest, secondary brain damage caused by hypoxia or hypercapnia, and aspiration pneumonia [1]. In addition, intubation itself may also cause brain herniation in patients with elevated intracranial pressure (ICP), such as brain hematoma. Therefore, the purpose of airway management in patients with neurological damage is the maintenance of adequate oxygenation and respiration, as well as the prevention of aspiration. However, the procedure should be performed while considering the possibility of increasing intracranial pressure and cervical spine injury

\section{Endotracheal Intubation in Patients with TBI}

Intubation is common in the emergency room when traumatic brain surgery occurs due to an emergency in the operating room. This review discusses the airway management of patients with head trauma upon arrival to the emergency room.

(c) This is an open-access article distributed under the terms of the Creative Commons Attribution Non-Commercial License (http://creativecommons.org/ licenses/by-nc/4.0/), which permits unrestricted non-commercial use, distribution, and reproduction in any medium, provided the original work is properly cited. 
Intubation should be performed without delay when respiratory arrest or cardiac arrest is imminent. Intubation must be performed even when the patient is unconscious, and aspiration due to vomiting is expected. The indications for intubation are inadequate oxygenation, improper respiration, loss of laryngeal reflex, and when neurological dysfunction and cardiopulmonary dysfunction are expected [2]. However, intubation itself can cause severe hemodynamic changes, and this risk should be considered in risk-benefit analyses. Rapid sequence intubation should be performed while considering increased ICP to prevent secondary brain injury [3-5]. Increased ICP can be expected particularly if the patient is unconscious, has one or both pupils dilated, or assumes a decerebrate posture [6]. Additionally, ICP can arise as a reflex sympathetic response due to intubation and direct laryngeal reflex. Comatose patients appear to have no reaction, but the stimulation of intubation may increase ICP [7]. Therefore, intubation following only muscle relaxant administration should be discouraged in patients with increased ICP. Intubation should be performed gently by experienced technicians to minimize irritation. The use of lidocaine $(1.5 \mathrm{mg} / \mathrm{kg}$, intravenous [IV]), esmolol (1-2 mg/kg, IV), fentanyl (2-3 $\mu \mathrm{g} / \mathrm{kg}$, IV), propofol (2 mg/kg, IV), ketamine ( $2 \mathrm{mg} / \mathrm{kg}$, IV), and muscle relaxants is also required [8-14].

\section{Can Ketamine be used in TBI Patients?}

Recent studies have reported the features of ketamine [15, 16]. Studies of ketamine since the 1970s have showen that its administration alone increases ICP in brain injury patients [1719]. Therefore, ketamine should not be used in these patients. However, sedative and analgesic medications, such as barbiturates, opioids, and propofol, can decrease blood pressure in TBI patients, consequently decreasing cerebral perfusion pressure (CPP). Contrary to previous reports, ketamine was shown to decrease ICP during interventions that can increase ICP. BarJoseph et al. [12] monitored blood pressure, ICP, and CPP for $10 \mathrm{~min}$ after ketamine $(1-1.5 \mathrm{mg} / \mathrm{kg})$ administration to lower markedly elevated ICP and reported that ketamine was a very effective and safe medication for TBI patients because it decreased ICP during interventions that can increase ICP, without lowering CPP or mean arterial pressure (MAP). Jabre et al. [20] compared etomidate and ketamine use during rapid sequence intubation in acutely ill patients and demonstrated that the ventilator weaning time, vasopressor weaning time, and 28day survival rates were not different between these medications; however, adrenal insufficiency was higher in the etomidate group. Comparison of the sequential organ failure assessment score revealed that ketamine was superior to etomidate in septic patients and showed better 28-day survival rates.

\section{Prevention of ICP Elevation after Intubation}

Two techniques to prevent an additional increase in ICP after intubation are an immediate head elevation after intubation, or tracheal intubation in the head-elevated position, if possible. MAP should be always maintained over $80-100 \mathrm{mmHg}$, and CPP should be maintained over $60 \mathrm{mmHg}$, if ICP monitoring is possible, with adequate analgesic and sedative administration for pain control. Notably, hypoventilation must be prevented. It is important to use $100 \%$ oxygen to maintain adequate pre-oxygenation before induction and maintain peripheral oxygen saturation over $94 \%$. However, the oxygen concentration should be lowered to maintain $\mathrm{FIO}_{2}$ at 0.5 or $\mathrm{PaO}_{2}$ within $110-300 \mathrm{mmHg}$ when the patient is hemodynamically stabilized and oxygenated adequately after intubation (Table 1) [21].

\section{Risks and Benefits of Pre-hospital Endotracheal Intubation}

Whether paramedics should perform endotracheal intubation in TBI patients or it should be performed in the emergency room is controversial. The use of sedatives and muscle relaxants is also controversial [22-29]. Wang et al. [30] reported a retrograde study that compared two groups of 4,098 TBI patients with similar disease and similar age who received pre-hospital intubation or hospital intubation. Patients who received prehospital intubation had a 3.99-fold higher mortality rate than hospital intubation patients. Stiell et al. [31] compared major trauma patients who received pre-hospital intubation and patients who did not undergo this procedure. There was no difference in the overall survival rate, but major trauma patients with a GCS below 9 who received out-of-hospital intubation had a lower survival rate. A study of 2,135 severe TBI patients with a GCS of 8 or below demonstrated that patients with outof-hospital advanced airway management had a higher mortality rate on day 28 and a worse 6-month neurological outcome than patients who received advanced airway management at

Table 1. Notes of Caution for Endotracheal Intubation in Patients with Elevated Intracranial Pressure

Head elevation immediately after intubation.

Intubate in the reverse Trendelenberg position if possible.

Use adequate sedative or analgesics and muscle relaxants to prevent

reflex sympathetic response during intubation

Avoid aspiration

Avoid hypoventilation because it may increase ICP.

Avoid hyperventilation because cerebral vasoconstriction increases

injury to the ischemic area.

Avoid hypoxemia because it exacerbates cerebral injury.

Maintain moderate hyperoxemia $\left(\mathrm{PaO}_{2} 110-300 \mathrm{mmHg}\right)$.

Maintain cerebral perfusion pressure $>60 \mathrm{mmHg}$. 
the emergency department [32]. The following reasons for the poor results for out-of-hospital advanced airway management are suspected: 1) suboptimal paramedic training; 2) lack of intubation skills (such as holding a laryngoscope for a long time); 3) iatrogenic hypotension and bradycardia; and 4) intubation failure due to insufficient use of muscle relaxants [23,33-36]. Unintended hyperventilation after intubation can decrease brain oxygen delivery and perfusion, which are the most important causes of poor outcomes [37]. By contrast, Bemard et al. [27] reported that brain trauma patients older than 15 years with a GCS of 9 or below with rapid sequence intubation (3 min of preoxygenation and intubation under monitoring by pulse oximetry, end-tidal $\mathrm{CO}_{2}$ measurement, and electrocardiography, and medications, such as fentanyl, midazolam, and succinylcholine) had a better neurological outcome 6 months after the injury. The paramedic rapid sequence intubation group exhibited better results because this group received $100 \%$ oxygen via an endotracheal tube during transfer to the hospital, which increased the oxygen partial pressure in the blood and lessened neurological injury. Both groups showed similar oxygen saturation. Therefore, hyperoxia may reduce neurological injury. Davis et al. [38] reported that TBI patients who had $\mathrm{PaO}_{2}$ values between 110 and $487 \mathrm{mmHg}$ with mild to moderate hyperoxemia on hospital arrival exhibited decreased mortality rates. However, extreme hyperoxemia increases mortality, likely due to hyperoxic cerebral vasoconstriction and oxygen free-radical formation [39-42]. The optimal oxygen tension is not known, but normoventilation and mild hyperoxemia using mechanical ventilation are ideal because hypocapnia (end-tidal $\mathrm{CO}_{2}<35 \mathrm{mmHg}$ ) can cause cerebral vasoconstriction that leads to secondary brain injury, and hypercapnia can increase ICP via cerebral vasodilation.

\section{Assessment of Cervical Spine Injury}

The possibility of a cervical spine injury in a blunt trauma patient is approximately $1.8 \%$ [43]. The most common site of injury is the cervical spine 2 (C-spine 2, C2), and C6 and C7 are vulnerable [44]. The probability of a C-spine injury increases in the elderly, because of degenerative changes in the spine [45]. However, head injury patients are approximately fourfold more likely to have additional $\mathrm{C}$-spine injuries than those without head injury. Patients with a GCS below 8 also have a higher likelihood of additional C-spine injury [46]. Demetriades et al. [47] examined 14,755 patients who visited a major trauma center over a 5-year period and reported that the incidence of $\mathrm{C}$-spine injury was $2 \%$. However, the incidence of $\mathrm{C}$-spine injury rose to $10.2 \%$ in patients with a GCS of 8 or below. The possibility of damage to the cervical spine should always be considered in patients with head trauma until it can be excluded. However, the following circumstances must be considered to exclude the possibility of C-spine injury: 1) the absence of tenderness in the central portions of the C-spine, 2) no focal neurological deficit, 3) clear consciousness, 4) no evidence of intoxication, and 5) no distracting damage [48].

\section{C-spine Anatomy and Injury Mechanisms}

To understand the damage caused by flexion or extension of the C-spine during intubation, we will review the anatomy of the $\mathrm{C}$-spine and its damage mechanism. The atlanto-occipital joint is responsible for $50 \%$ of the neck flexion and extension, and the atlanto-axial joint is responsible for $50 \%$ of the neck rotation. Because there is no intervertebral disc at these two joints, there is a high likelihood of inflammatory arthritis [49]. Anterior longitudinal ligament (ALL) prevents hyperextension, while posterior longitudinal ligament (PLL) prevents hyperflexion. The widest portion of the spinal canal is $\mathrm{C} 1-\mathrm{C} 3$, with a mid-sagittal diameter of approximately $16-30 \mathrm{~mm}$. The narrowest part is C4$\mathrm{C} 7$, with a mid-sagittal diameter of $14-23 \mathrm{~mm}$. In this region, hyperextension can reduce the canal diameter by approximately 2-3 mm; thus, caution is needed in patients with hyperextension injury [50]. Axial compression injury is often caused by activities such as diving, and bursting fracture of the atlas is also called a "Jefferson fracture". This site has a wide canal diameter, and neurological injury is rare. However, when the transverse ligament is damaged as well, it can become very unstable and requires caution [51]. An odontoid facture occurs when flexion, extension, and rotation mechanisms are mixed. There are three types. In a type 1 odontoid fracture, only the tip of the dens is detached with no significant influence on instability. In a type 2 odontoid fracture, the base of the dens is broken. When fractures are associated with transverse ligament injury, it makes very unstable with a high mortality rate. In a type 3 odontoid fracture, the C2 body breaks off with the dens, with the atlas and occiput moving as a single mass, making it highly unstable. A C5 flexion teardrop fracture commonly occurs by a flexion mechanism [51]. It is usually caused by car accidents or a diving injury, with the body of the vertebra displacing posteriorly, often causing neurologic impairment. Bilateral facet dislocation is the most serious damage, with the complete destruction of both the ALL and PLL commonly accompanying neurologic injury. An example of an extension mechanism fracture would be a hangman's fracturei.e., fracture of the pedicle of an axis. It can be caused by severe hyperextension caused by diving or a car accident, and spinal cord injury is not severe because the spinal canal is wide at the $\mathrm{C} 2$ level. Of the fractures caused by extension injury, the teardrop fracture of the $\mathrm{C} 2$ is termed an 'unstable injury'. It is caused by the tension of the ALL, which leads to the breakage of the anterior body of the C2. Although the neurological deficit is not severe, extension should be performed carefully [51]. Common 
Table 2. Common Cervical Spine Fractures according to Injury Mechanism

\begin{tabular}{ll}
\hline \multicolumn{1}{c}{ Injury mechanism } & \multicolumn{1}{c}{ Common cervical spine fracture site } \\
\hline Axial compression mechanism & Jefferson fracture (unilateral or bilateral fractures of the anterior and posterior arches of C1) \\
Multiple mechanisms & Odontoid fractures \\
& - Type 1: avulsion fracture of the tip of the dens \\
& - Type 2: localized fracture of the base of the dens \\
& - Type 3: extended fracture into the C2 body \\
& C5 flexion tear-drop fracture (anterior inferior aspect of the C5 body) \\
Flexion mechanism & Bilateral facet dislocation \\
& Clay shoveler fracture (an avulsion fracture of the C7 spinous process) \\
& Hangman's fracture (pedicle fractures of the C1 or C2) \\
Extension mechanism & C2 extension tear-drop fracture (avulsion fracture of the anterior inferior aspect) of the body \\
\hline
\end{tabular}

cervical fractures according to injury mechanism are summarized in Table 2.

\section{Clinical Notes of C-spine Injury and Manual In-line Stabilization (MILS)}

Airway management of patients with C-spine injury should be performed using the MILS technique to minimize cervical movement, and rapid sequence intubation should be applied. To perform the MILS exactly, the assistant must maintain the patient's head in a neutral position while fixing it against the force exerted during endotracheal intubation [51]. The MILS method is the best way to effectively limit the movement of the C-spine at the lowest cost. In a study using magnetic resonance imaging, De Lorenzo et al. [52] reported placing a pillow approximately $2-\mathrm{cm}$ high beneath the head increases the spinal canal/spinal cord ratio at the C5-6 levels, a region that is injured frequently. The application of the MILS maneuver decreased C-spine extension when exposing the arytenoid under a direct laryngoscope [53]. However, the MILS technique does not completely eliminate C-spine movement. Lennarson et al. [54] compared $\mathrm{C}$-spine movement when MILS was performed, and it was not eliminated while applying 7-10 pounds of traction in a cardaver with C4-5 transection. C-spine extension was less in the case of traction. However, cervical subluxation was increased by applying the MILS technique. Distraction was reported to increase during traction and decrease during MILS. Therefore, compared with emergency situations in which the location of damage is unknown because the site of injury has not been assessed, the application of the MILS technique reduces cervical extension.

\section{Laryngoscopic View according to Neck Stabilization Technique}

Patients with cervical spine injuries have limitations when opening their mouth for intubation or to position an airway because they are wearing cervical collars [55]. The anterior portion of the cervical collar must be removed, and another anesthetic assistant must hold the patient's head on the bedside to minimize patient movement during intubation [51]. It is known that MILS reduces mouth opening and worsens the laryngoscopic view [56]. By performing MILS, the rate of Cormack-Lehane grade worsening of $>1$ grade is $35.6 \%$, while the possibility of it worsening $>2$ grades is approximately $10 \%$ [57]. In addition, mouth opening decreases by approximately $10 \mathrm{~mm}$ depending on the type of cervical collar [55].

\section{C-spine Movement during Intubation}

Sawin et al. [58] used fluoroscopy to record a movie of Cspine movement in a normal patient during intubation. At the time of blade insertion, the spine moved little, but when the blade was elevated for vocal cord exposure, extension occurred from the occiput to the $\mathrm{C} 1$ level and flexion occurred at the $\mathrm{C} 2$ C5 level. However, using a video laryngoscope for intubation without direct visualization and aligning the oral, laryngeal, and tracheal axis could minimize the movement of the cervical spine.

\section{Comparison by Airway Maintenance Equipment in Cervical Spine Patients}

Completely transecting cadavers at the C5-6 level, and compared to the spinal movement using the Miller straight blade, Macintosh curved blade, and Corazelli-London-Mccoy hinged blade, the MILS technique showed significantly lower anteroposterior (AP) displacement than the cervical collar [59]. In terms of AP and axial movement with MILS, use of the Miller straight blade showed better results than the Macintosh curved blade and Corazelli-London-Mccoy hinged blade. Watts et al. [60] conducted a study on 29 patients undergoing general anesthesia using the Bullard laryngoscope and Macintosh laryngoscope, and compared C-spine extension, time to intubation, and grade of laryngeal view between patients using and not using MILS. 
Under MILS, use of the Bullard laryngoscope reduced C-spine extension at all spine levels during intubation but increased the intubation time to about twice that using the Macintosh blade. Using a new type of video-laryngoscope called the AirWay Scope $^{\circledR}$ (AWS, Pentax, ToKyo, Japan), the extension movement from the occiput to $\mathrm{C} 4$ decreased greatly compared with the Macintosh laryngoscope [61]. Another type, the AirTraq laryngoscope (King Medical Systems, Newark, DE, USA), also decreased extension of the C2-C5 spine and C5-thoracic segment spine by up to $66 \%$ compared with the Macintosh laryngoscope, while the time to intubation was similar, leading to the conclusion that the AirTraq is better for patients with cervical spine injury [62]. Comparing cervical spine motion during intubation using the Glidescope ${ }^{\circledR}$ (Verathon Inc., Bothell, WA, USA), the Macintosh no. 3 blade, and the lightwand (Trachlight ${ }^{\circledR}$, Laerdal, Armonk, NY, USA) under MILS, the Glidescope ${ }^{\circledR}$ decreased C2-C5 motion, and the lightwand decreased extension motion at the occiput-C1, C1-C2, C2-C5, and C5-thoracic levels [63]. Comparing direct laryngoscopy and the Glidescope ${ }^{\circledR}$ under the MILS technique in 20 patients without C-spine pathology, 100\% of patients using the Glidescope ${ }^{\circledR}$ were viewed as CormackLehane grade $1,65 \%$ of patients using direct laryngoscopy were viewed as Cormack-Lehane grade 2, and 35\% of patients using direct laryngoscopy were viewed as Cormack-Lehane grade 3. The Glidescope ${ }^{\circledR}$ offered better glottis visualization than the direct laryngoscope, with the same C-spine movement [64]. Malik et al. [65] performed a study to identify a novel laryngoscope technique using MILS; after comparison, the Pentax AWS showed higher probability of grade 1 on Cormack-Lehane laryngoscope view than the Glidescope ${ }^{\circledR}$, the Truview EVO2, and the Macintosh blade, indicating that the AWS was the most useful. Additionally, Liu et al. [66] compared the Glidescope ${ }^{\circledR}$ and AWS; the AWS required half the time to complete the tracheal intubation process, with easier intubation. However, in terms of cervical movement, fiber-optic bronchoscope-guided nasal intubation showed the least cervical movement, although it is difficult for novices to perform [67].

\section{C-spine Movement during Pre-intubation Maneuvers}

In a cadaver study, we have learned that pre-intubation techniques such as the chin lift or jaw thrust can narrow the space available for a cord. However, the cricoid pressure does not further increase the movement of the cranio-cervical junction [68]. Hauswald et al. [69] reported that mask ventilation requires more attention than any other procedure because it worsens cervical spine displacement.

\section{Summary}

In TBI patients, mild hyperoxemia and normocapnia are helpful in preventing secondary brain injury, and use of appropriate sedatives and muscle relaxants is recommended. The management of patients with head trauma should always consider C-spine motion restriction because there is a possibility of head trauma accompanied by cervical spine injury. Performing MILS ensures safe endotracheal intubation, but the procedure itself makes intubation difficult. Endotracheal intubation with a video-laryngoscope is easy to learn and has a good field of view, so its use is increasing. However, the Glidescope ${ }^{\circledR}$ does not decrease cervical movement compared with a direct laryngoscope, and a video laryngoscope has better vocal cord visualization, therefore ensuring a higher rate of successful endotracheal intubation.

\section{References}

1. Chesnut RM, Marshall LF, Klauber MR, Blunt BA, Baldwin N, Eisenberg HM, et al. The role of secondary brain injury in determining outcome from severe head injury. J Trauma 1993; 34: 216-22.

2. Seder DB, Riker RR, Jagoda A, Smith WS, Weingart SD. Emergency neurological life support: airway, ventilation, and sedation. Neurocrit Care 2012; 17 Suppl 1: S4-20.

3. Coplin WM, Pierson DJ, Cooley KD, Newell DW, Rubenfeld GD. Implications of extubation delay in brain-injured patients meeting standard weaning criteria. Am J Respir Crit Care Med 2000; 161: 1530-6.

4. Sagarin MJ, Barton ED, Chng YM, Walls RM. Airway management by US and Canadian emergency medicine residents: a multicenter analysis of more than 6,000 endotracheal intubation attempts. Ann Emerg Med 2005; 46: 328-36.

5. Li J, Murphy-Lavoie H, Bugas C, Martinez J, Preston C. Complications of emergency intubation with and without paralysis. Am J Emerg Med 1999; 17: 141-3.

6. Gabriel EJ, Ghajar J, Jagoda A, Pons PT, Scalea T, Walters BC. Guidelines for prehospital management of traumatic brain injury. J Neurotrauma 2002; 19: 111-74.

7. Bedford RF, Persing JA, Pobereskin L, Butler A. Lidocaine or thiopental for rapid control of intracranial hypertension? Anesth Analg 1980; 59: 435-7. 
8. Salhi B, Stettner E. In defense of the use of lidocaine in rapid sequence intubation. Ann Emerg Med 2007; 49: 84-6.

9. Feng CK, Chan KH, Liu KN, Or CH, Lee TY. A comparison of lidocaine, fentanyl, and esmolol for attenuation of cardiovascular response to laryngoscopy and tracheal intubation. Acta Anaesthesiol Sin 1996; 34: 61-7.

10. Reynolds SF, Heffner J. Airway management of the critically ill patient: rapid-sequence intubation. Chest 2005; 127: $1397-412$.

11. Hug CC Jr, McLeskey CH, Nahrwold ML, Roizen MF, Stanley TH, Thisted RA, et al. Hemodynamic effects of propofol: data from over 25,000 patients. Anesth Analg 1993; 77(4 Suppl): S21-9.

12. Bar-Joseph G, Guilburd Y, Tamir A, Guilburd JN. Effectiveness of ketamine in decreasing intracranial pressure in children with intracranial hypertension. J Neurosurg Pediatr 2009; 4: 40-6.

13. Långsjö JW, Maksimow A, Salmi E, Kaisti K, Aalto S, Oikonen V, et al. S-ketamine anesthesia increases cerebral blood flow in excess of the metabolic needs in humans. Anesthesiology 2005; 103: 258-68.

14. Kovarik WD, Mayberg TS, Lam AM, Mathisen TL, Winn HR. Succinylcholine does not change intracranial pressure, cerebral blood flow velocity, or the electroencephalogram in patients with neurologic injury. Anesth Analg 1994; 78: 469-73.

15. Ryu T, Jung JY. Re-evaluation of the applicability of ketamine in neurosurgical anesthesia. Anesth Pain Med 2014; 9: 231-6.

16. Himmelseher S, Durieux ME. Revising a dogma: ketamine for patients with neurological injury? Anesth Analg 2005; 101: 524-34.

17. Crumrine RS, Nulsen FE, Weiss MH. Alterations in ventricular fluid pressure during ketamine anesthesia in hydrocephalic children. Anesthesiology 1975; 42: 758-61.

18. Gibbs JM. The effect of intravenous ketamine on cerebrospinal fluid pressure. Br J Anaesth 1972; 44: 1298-302.

19. Shaprio HM, Wyte SR, Harris AB. Ketamine anaesthesia in patients with intracranial pathology. Br J Anaesth 1972; 44: 1200-4.

20. Jabre P, Combes X, Lapostolle F, Dhaouadi M, Ricard-Hibon A, Vivien B, et al. Etomidate versus ketamine for rapid sequence intubation in acutely ill patients: a multicentre randomised controlled trial. Lancet 2009; 374: 293-300.

21. Seder DB, Mayer SA. Critical care management of subarachnoid hemorrhage and ischemic stroke. Clin Chest Med 2009; 30 : 103-22.

22. Davis DP, Fakhry SM, Wang HE, Bulger EM, Domeier RM, Trask AL, et al. Paramedic rapid sequence intubation for severe traumatic brain injury: perspectives from an expert panel. Prehosp Emerg Care 2007; 11: 1-8.

23. Davis DP, Idris AH, Sise MJ, Kennedy F, Eastman AB, Velky T, et al. Early ventilation and outcome in patients with moderate to severe traumatic brain injury. Crit Care Med 2006; 34: 1202-8.

24. Davis DP, Peay J, Serrano JA, Buono C, Vilke GM, Sise MJ, et al. The impact of aeromedical response to patients with moderate to severe traumatic brain injury. Ann Emerg Med 2005; 46: 115-22.

25. Davis DP, Dunford JV, Ochs M, Park K, Hoyt DB. The use of quantitative end-tidal capnometry to avoid inadvertent severe hyperventilation in patients with head injury after paramedic rapid sequence intubation. J Trauma 2004; 56: 808-14.

26. Spaite DW, Criss EA, Valenzuela TD, Meislin HW. Prehospital advanced life support for major trauma: critical need for clinical trials. Ann Emerg Med 1998; 32: 480-9.

27. Bernard SA, Nguyen V, Cameron P, Masci K, Fitzgerald M, Cooper DJ, et al. Prehospital rapid sequence intubation improves functional outcome for patients with severe traumatic brain injury: a randomized controlled trial. Ann Surg 2010; 252: 959-65.

28. Warner KJ, Cuschieri J, Copass MK, Jurkovich GJ, Bulger EM. The impact of prehospital ventilation on outcome after severe traumatic brain injury. J Trauma 2007; 62: 1330-6.

29. Klemen P, Grmec S. Effect of pre-hospital advanced life support with rapid sequence intubation on outcome of severe traumatic brain injury. Acta Anaesthesiol Scand 2006; 50: 1250-4.

30. Wang HE, Peitzman AB, Cassidy LD, Adelson PD, Yealy DM. Out-of-hospital endotracheal intubation and outcome after traumatic brain injury. Ann Emerg Med 2004; 44: 439-50.

31. Stiell IG, Nesbitt LP, Pickett W, Munkley D, Spaite DW, Banek J, et al. The OPALS Major Trauma Study: impact of advanced life-support on survival and morbidity. CMAJ 2008; 178: 1141-52.

32. Wang HE, Brown SP, MacDonald RD, Dowling SK, Lin S, Davis D, et al. Association of out-of-hospital advanced airway management with outcomes after traumatic brain injury and hemorrhagic shock in the ROC hypertonic saline trial. Emerg Med J 2014; 31: 186-91.

33. Wang HE, Kupas DF, Hostler D, Cooney R, Yealy DM, Lave JR. Procedural experience with out-of-hospital endotracheal intubation. Crit Care Med 2005; 33: 1718-21.

34. Wang HE, Lave JR, Sirio CA, Yealy DM. Paramedic intubation errors: isolated events or symptoms of larger problems? Health Aff (Millwood) 2006; 25: 501-9.

35. Wang HE, Simeone SJ, Weaver MD, Callaway CW. Interruptions in cardiopulmonary resuscitation from paramedic endotracheal intubation. Ann Emerg Med 2009; 54: 645-52.

36. Dunford JV, Davis DP, Ochs M, Doney M, Hoyt DB. Incidence of transient hypoxia and pulse rate reactivity during paramedic rapid sequence intubation. Ann Emerg Med 2003; 42: 721-8.

37. Davis DP, Dunford JV, Poste JC, Ochs M, Holbrook T, Fortlage D, et al. The impact of hypoxia and hyperventilation on outcome after paramedic rapid sequence intubation of severely head-injured patients. J Trauma 2004; 57: 1-8.

38. Davis DP, Meade W, Sise MJ, Kennedy F, Simon F, Tominaga G, et al. Both hypoxemia and extreme hyperoxemia may be detrimental in patients with severe traumatic brain injury. J Neurotrauma 2009; 26: 2217-23.

39. Floyd TF, Clark JM, Gelfand R, Detre JA, Ratcliffe S, Guvakov D, et al. Independent cerebral vasoconstrictive effects of hyperoxia and 
accompanying arterial hypocapnia at 1 ATA. J Appl Physiol (1985) 2003; 95: 2453-61.

40. Zhilyaev SY, Moskvin AN, Platonova TF, Gutsaeva DR, Churilina IV, Demchenko IT. Hyperoxic vasoconstriction in the brain is mediated by inactivation of nitric oxide by superoxide anions. Neurosci Behav Physiol 2003; 33: 783-7.

41. Ahn ES, Robertson CL, Vereczki V, Hoffman GE, Fiskum G. Synthes Award for Resident Research on Brain and Craniofacial Injury: normoxic ventilatory resuscitation after controlled cortical impact reduces peroxynitrite-mediated protein nitration in the hippocampus. Clin Neurosurg 2005; 52: 348-56.

42. Li J, Gao X, Qian M, Eaton JW. Mitochondrial metabolism underlies hyperoxic cell damage. Free Radic Biol Med 2004; 36: 1460-70.

43. Crosby ET, Lui A. The adult cervical spine: implications for airway management. Can J Anaesth 1990; 37: 77-93.

44. Goldberg W, Mueller C, Panacek E, Tigges S, Hoffman JR, Mower WR. Distribution and patterns of blunt traumatic cervical spine injury. Ann Emerg Med 2001; 38: 17-21.

45. Robitaille A. Airway management in the patient with potential cervical spine instability: continuing professional development. Can J Anaesth 2011; 58: 1125-39.

46. Holly LT, Kelly DF, Counelis GJ, Blinman T, McArthur DL, Cryer HG. Cervical spine trauma associated with moderate and severe head injury: incidence, risk factors, and injury characteristics. J Neurosurg 2002; 96(3 Suppl): 285-91.

47. Demetriades D, Charalambides K, Chahwan S, Hanpeter D, Alo K, Velmahos G, et al. Nonskeletal cervical spine injuries: epidemiology and diagnostic pitfalls. J Trauma 2000; 48: 724-7.

48. Hoffman JR, Mower WR, Wolfson AB, Todd KH, Zucker MI. Validity of a set of clinical criteria to rule out injury to the cervical spine in patients with blunt trauma. National Emergency X-Radiography Utilization Study Group. N Engl J Med 2000; 343: $94-9$.

49. Kim DH, Hilibrand AS. Rheumatoid arthritis in the cervical spine. J Am Acad Orthop Surg 2005; 13: 463-74.

50. Devereaux MW. Anatomy and examination of the spine. Neurol Clin 2007; 25: 331-51.

51. Pimentel L, Diegelmann L. Evaluation and management of acute cervical spine trauma. Emerg Med Clin North Am 2010; 28 : 719-38.

52. De Lorenzo RA, Olson JE, Boska M, Johnston R, Hamilton GC, Augustine J, et al. Optimal positioning for cervical immobilization. Ann Emerg Med 1996; 28: 301-8.

53. Hastings RH, Wood PR. Head extension and laryngeal view during laryngoscopy with cervical spine stabilization maneuvers. Anesthesiology 1994; 80: 825-31.

54. Lennarson PJ, Smith DW, Sawin PD, Todd MM, Sato Y, Traynelis VC. Cervical spinal motion during intubation: efficacy of stabilization maneuvers in the setting of complete segmental instability. J Neurosurg 2001; 94(2 Suppl): 265-70.

55. Goutcher CM, Lochhead V. Reduction in mouth opening with semi-rigid cervical collars. Br J Anaesth 2005; 95: 344-8.

56. Heath KJ. The effect of laryngoscopy of different cervical spine immobilisation techniques. Anaesthesia 1994; 49: 843-5.

57. Nolan JP, Wilson ME. Orotracheal intubation in patients with potential cervical spine injuries. An indication for the gum elastic bougie. Anaesthesia 1993; 48: 630-3.

58. Sawin PD, Todd MM, Traynelis VC, Farrell SB, Nader A, Sato Y, et al. Cervical spine motion with direct laryngoscopy and orotracheal intubation. An in vivo cinefluoroscopic study of subjects without cervical abnormality. Anesthesiology 1996; 85: 26-36.

59. Gerling MC, Davis DP, Hamilton RS, Morris GF, Vilke GM, Garfin SR, et al. Effects of cervical spine immobilization technique and laryngoscope blade selection on an unstable cervical spine in a cadaver model of intubation. Ann Emerg Med 2000; 36: 293-300.

60. Watts AD, Gelb AW, Bach DB, Pelz DM. Comparison of the Bullard and Macintosh laryngoscopes for endotracheal intubation of patients with a potential cervical spine injury. Anesthesiology 1997; 87: 1335-42.

61. Maruyama K, Yamada T, Kawakami R, Hara K. Randomized cross-over comparison of cervical-spine motion with the AirWay Scope or Macintosh laryngoscope with in-line stabilization: a video-fluoroscopic study. Br J Anaesth 2008; 101: 563-7.

62. Turkstra TP, Pelz DM, Jones PM. Cervical spine motion: a fluoroscopic comparison of the AirTraq Laryngoscope versus the Macintosh laryngoscope. Anesthesiology 2009; 111: 97-101.

63. Turkstra TP, Craen RA, Pelz DM, Gelb AW. Cervical spine motion: a fluoroscopic comparison during intubation with lighted stylet, GlideScope, and Macintosh laryngoscope. Anesth Analg 2005; 101: 910-5.

64. Robitaille A, Williams SR, Tremblay MH, Guilbert F, Thériault M, Drolet P. Cervical spine motion during tracheal intubation with manual in-line stabilization: direct laryngoscopy versus GlideScope videolaryngoscopy. Anesth Analg 2008; 106: 935-41.

65. Malik MA, Maharaj CH, Harte BH, Laffey JG. Comparison of Macintosh, Truview EVO2, Glidescope, and Airwayscope laryngoscope use in patients with cervical spine immobilization. Br J Anaesth 2008; 101: 723-30.

66. Liu EH, Goy RW, Tan BH, Asai T. Tracheal intubation with videolaryngoscopes in patients with cervical spine immobilization: a randomized trial of the Airway Scope and the GlideScope. Br J Anaesth 2009; 103: 446-51.

67. Brimacombe J, Keller C, Künzel KH, Gaber O, Boehler M, Pühringer F. Cervical spine motion during airway management: a cinefluoroscopic study of the posteriorly destabilized third cervical vertebrae in human cadavers. Anesth Analg 2000; 91: 1274-8.

68. Donaldson WF 3rd, Heil BV, Donaldson VP, Silvaggio VJ. The effect of airway maneuvers on the unstable C1-C2 segment. A cadaver study. Spine (Phila Pa 1976) 1997; 22: 1215-8.

69. Hauswald M, Sklar DP, Tandberg D, Garcia JF. Cervical spine movement during airway management: cinefluoroscopic appraisal in human cadavers. Am J Emerg Med 1991; 9: 535-8. 